\title{
Estimating investor preferences towards portfolio return distribution in investment funds
}

\author{
Margareta Gardijan ${ }^{1, *}$ and Tihana Škrinjarić ${ }^{1}$ \\ ${ }^{1}$ Faculty of Economics and Business, University of Zagreb \\ Trg J. F. Kennedyja 6, 10000 Zagreb, Croatia \\ E-mail: 〈\{mgardijan, tskrinjaric $\} @ e f z g . h r\rangle$
}

\begin{abstract}
Recent research in the field of investor preference has emphasised the need to go beyond just simply analyzing the first two moments of a portfolio return distribution used in a MV (mean-variance) paradigm. The suggestion is to observe an investor's utility function as an $n^{\text {th }}$ order Taylor approximation. In such terms, the assumption is that investors prefer greater values of odd and smaller values of even moments. In order to investigate the preferences of Croatian investment funds, an analysis of the moments of their return distribution is conducted. The sample contains data on monthly returns of 30 investment funds in Croatia for the period from January 1999 to May 2014. Using the theoretical utility functions (DARA, CARA, CRRA), we compare changes in their preferences when higher moments are included. Moreover, we investigate an extension of the CAPM model in order to find out whether including higher moments can explain better the relationship between the awards and risk premium, and whether we can apply these findings to estimate preferences of Croatian institutional investors. The results indicate that Croatian institutional investors do not seek compensation for bearing greater market risk.
\end{abstract}

Keywords: higher distribution moments, investor preferences, higher moments CAPM, Croatian investment funds

Received: September 22, 2014; accepted: December 30, 2014; available online: March 30, 2015

DOI: $10.17535 /$ crorr.2015.0001

\section{Introduction}

The modern portfolio theory (MPT) lies upon the assumption of normal distribution of stock returns, besides other assumptions (such as efficient market hypothesis, equal expectations of all investors on the market, etc.). This means that only the expected return (distribution's first moment) and the variance (second moment) are sufficient to explore an investor's utility function. In that way, the Markowitz portfolio selection model [45], the CAPM (Capital Asset Pricing Model) [40, 57] and other popular MPT concepts, are based on the

${ }^{*}$ Corresponding author. 
assumption that investors take into consideration only the first two distribution moments of an asset's returns when making investment decisions. Microeconomic theory has proven that investors seek to maximize the first moment (reward) and aim to minimize the second moment (risk) $([9,35,41]$, etc.). Thus, for several decades, it has been common practice to include the first two distribution moments when dealing with theoretical and empirical work on asset pricing (see [16, 49, 58, 20, 44, 11], etc.).

However, since the beginning of forming the MPT, both empirical and theoretical papers dealing with preferences towards higher moments of return distributions have been emerging. Empirical proof of the non-normality of return distributions ranges back in the beginning of the 1960s (see [42, 43, 14, 17], etc.). Financial series were found to be leptokurtic and skewed, which did not comply with the assumptions of asset pricing models. Subsequently, the results that arise from these models can be misleading. Motivated by these findings, many authors began basing preferences towards higher portfolio moments on theoretical foundations ([55, 54, 28, 29, 30, 27], etc.). Microeconomic analysis enabled the development of the basic models of investor's utility functions (see, for example, [8]) by introducing the third and fourth distribution moments in utility analysis. The third moment - skewness relates to the number of above or below average returns, whilst the fourth moment - kurtosis relates to the likelihood of above or below average returns. Since the 1970s, there have been numerous theoretical and empirical papers treating higher moments in investments (see $[1,4,6,7,10,28,29,30,22,33,34$, $38,50,13]$, etc.).

Nowadays, ordinarily the assumption is to base investor's preferences on the first four distribution moments. Besides the first two moments, investors now aim to maximize the third and minimize the fourth moment. Moreover, the investor's utility function is now based on the first four distribution moments, i.e. the analysis models preferences are based on higher moments. If this assumption is correct, empirical findings should provide proof that investors aim to maximize the odd and minimize the even moments. Moreover, the famous CAPM approach was found to explain inadequately the relationship between systematic risk and asset return (see [52, 53, 31, 18], etc.). Thus, both empirical and theoretical analyses focus on further developing the original model (see [21, $38]$ ). Numerous studies have concluded that higher moments aid in explaining the relationship between risk premium and awards ([19, 26, 12, 47], etc.). Messis et al. [47] examined investor preferences in Greece for the period from 2001 to 2005. The results of their analysis have showed that investors may prefer positive skewness, but they are compensated by a higher return for bearing a higher risk. Fang and Lai [19] analyzed NYSE investor preferences using the CAPM framework. They concluded that investors are compensated by higher than expected returns for bearing systematic variance and kurtosis risk. Hasan et al. [24] observed the Bangladesh stock market and its investors. The results 
from analyzing the period from 2005 to 2009 led to similar conclusions as the previous mentioned papers. Including higher moments in CAPM can adequately describe investor preferences. The emerging markets have been examined by Dittmar [15], Harvey and Siddique [23], Hwang and Satchell [26], etc. and have shown that a higher CAPM moment explains investor preferences better than the original model.

This paper investigates two aspects of incorporating higher moments into the analysis. The first one is the preferences of Croatian institutional investors or more precisely, the preferences of Croatian investment funds when higher moments are taken into consideration. This approach can reveal whether the investment funds manage higher moments of portfolio return distribution in order to increase their utility according to microeconomic theory. The second aspect is an empirical attempt to investigate whether applying these theoretical preferences towards third and fourth distribution moments makes sense on the Croatian capital market. In order to do this, we need to estimate the impact of higher order moments on excess returns of funds by applying the extended CAPM model that incorporates higher moments. Since this is the most popular model in evaluating assets and funds, one of the goals of this paper is to explore the consequences of adding higher moments into the pricing model and then compare the results to the original model. This can facilitate adapting standard theory to the requirements of Croatian investors and can be beneficial in applying the correct investment evaluation models. Thus, the paper is structured as follows: Chapter 2 deals with theoretical foundations in analyzing higher moments; Chapter 3 explains the methodology of this study; Chapter 4 provides empirical research and finally, conclusions are presented in Chapter 5.

\section{Theoretical foundations for analyzing higher moments}

This section adheres to the methodology given in [56, 33, 34, 32], etc. Let us consider an investor who aims to maximize the expected von NeumannMorgenstein utility function $U(R)$,

$$
E(U(R))=\int_{-\infty}^{+\infty} U(R) F(R) d R
$$

where $R=1+r, r$ is the one-period return on assets and $F(R)$ is the probability distribution of $R$. If the utility function is continuously differentiable, it can be approximated as a Taylor series expansion:

$$
U(R)=\sum_{n=0}^{N} \frac{U^{(n)}[E(R)] \cdot[R-E(R)]^{n}}{n !}+R_{N}
$$


where $U^{(n)}$ is the $n$-th derivative of the utility function and $R_{N}$ is the Taylor remainder. If the Taylor approximation converges towards the utility function (among other assumptions, see [34,39], etc.), the expected value of (2) is:

$$
E(U(R)) \approx \sum_{n=0}^{N} \frac{U^{(n)}[E(R)]}{n !} \cdot E\left[(R-E(R))^{n}\right] .
$$

Focusing solely on the first four moments means that (3) becomes:

$$
E(U(R)) \approx U[E(R)]+\frac{U^{(2)} E(R) \sigma^{2}}{2}+\frac{U^{(3)} E(R) s^{3}}{3 !}+\frac{U^{(4)} E(R) \kappa^{4}}{4 !},
$$

where $\sigma^{2}=E\left\{[R-E(R)]^{2}\right\} \quad$ (variance), $\quad s^{3}=E\left\{[R-E(R)]^{3}\right\} \quad$ (skewness) and $\kappa^{4}=E\left\{[R-E(R)]^{4}\right\}$ (kurtosis). Under the assumptions given in [56], it holds that:

$$
\begin{aligned}
& U^{(n)}(R)>0 \text { if } n \text { is odd } \\
& U^{(n)}(R)<0 \text { if } n \text { is even }
\end{aligned}
$$

with the expected utility given in (4) depending positively on the expected return and skewness, and negatively on variance and kurtosis. Since the expected return represents the reward for handling risky security, understanding its positive impact on the expected utility is simple. Furthermore, variance is the most popular risk measure in the MPT framework, thus, the reason why it negatively impacts the utility function becomes clear. The third moment skewness defines the asymmetry of the distribution. If asymmetry exists, it can be positive or negative, and the probabilities of extreme above- or below-average returns vary significantly. Arditti $[2,3]$ explains that investors are prone to positive distribution asymmetry, since positive asymmetry lowers the probability of extreme below-average returns. Consequently, the third moment exhibits a positive effect on the utility. Kurtosis indicates the roundness of a distribution peak and tail thickness. This refers to the probability of extreme events occurring, i.e. extreme returns; and Kemalbay et al. [36] explain that investors aim to minimize the kurtosis because it minimizes the probability. Thus, the reason why the fourth moment has a negative impact on the utility is the uncertainty of extreme events.

To determine the functional form of the expected utility function, some assumptions on its properties are required. Pratt [51], Arrow [5] and Kimball [37] state that the utility function should be characterised by the following properties: non-satiation, strict risk aversion, a strict decreasing of absolute risk aversion, a strict of decreasing absolute prudence and constant or increasing relative risk aversion [34:2]. Subsequently, three types of utility functions with these properties are defined by: 


$$
\begin{aligned}
& \text { CRRA .. U }(R)=\frac{R^{1-\gamma}}{1-\gamma}, \\
& \text { CARA.. } U(R)=-\frac{1}{\lambda e^{\lambda R},} \\
& \text { DARA...U(R) }=\ln (R),
\end{aligned}
$$

where CRRA denotes Constant Relative Risk Aversion, and $\gamma>0$ is the investor's relative risk aversion; $C A R A$ denotes Constant Absolute Risk Aversion, and $\lambda>0$ is the investor's absolute risk aversion, and DARA denotes Decreasing Absolute Risk Aversion (see [32]). Given that the investor's utility function is defined as (6), (7) or (8), the Taylor approximation in (4) is easier to compute. Based on empirical data, the magnitude of different moment impact on the expected utility can be determined.

This analysis can be extended to pricing models. The Capital Asset Pricing Model (CAPM) $[57,40]$ is a linear model for predicting systematic risk, where excess stock return is linear to non-diversifiable risk. It remains the most popular pricing model despite its many pitfalls (mostly found in its assumptions). The model is based on the assumption that normal return distributions and empirical tests over the decades have rejected its prediction ability (see [24] for a detailed list of papers). This has led to theoretical developments of higher moments in the CAPM model. The pioneering authors in this field were Rubinstein [54], Ingersoll [27], Graddy and Homaifar [21], who were later followed by the work of Dittmar [15], Fang and Lai [19], Jurczeno and Maillet [27], etc. The assumption is that there exist $I$ risky assets $(I \geq 4)$ and a risk-free asset on the market, and that the investor's utility function is as described in the first part of this chapter. The investor invests $w_{i}$ of his wealth into the $i$-th risky asset, $i \in\{1,2, \ldots, I\}$ and $w_{0}$ into the risk-free asset. The mean $E\left(R_{P}\right)$, variance $\sigma_{P}^{2}$, skewness $s_{P}^{3}$ and kurtosis $\kappa_{P}^{4}$ of the portfolio return is expressed as follows:

$$
\begin{aligned}
& E\left(R_{P}\right)=w_{0} R_{f}+w^{\prime} \boldsymbol{E} \\
& \sigma_{P}^{2}=\boldsymbol{w}^{\prime} \boldsymbol{\Omega} \boldsymbol{w} \\
& s_{P}^{3}=\boldsymbol{w}^{\prime} \Sigma(\boldsymbol{w} \otimes \boldsymbol{w}) \\
& \kappa_{P}^{4}=\boldsymbol{w}^{\prime} \Gamma(\boldsymbol{w} \otimes \boldsymbol{w} \otimes \boldsymbol{w})
\end{aligned}
$$

where $R_{f}$ denotes the risk free return, $\boldsymbol{w}$ is the vector of investor's holdings of risky assets, $\boldsymbol{E}$ is the vector of expected return of risky assets, $\boldsymbol{\Omega}$ is the variance-covariance matrix, $\boldsymbol{\Sigma}$ is the skewness-coskewness matrix and $\Gamma$ is the kurtosis-cokurtosis matrix. It holds true that $\boldsymbol{w}^{\prime} \mathbf{1}=1-w_{0}$, where $\mathbf{1}$ is the unitary vector. The investor's portfolio problem is now:

$$
\begin{aligned}
& \max _{w} E\left(U\left(R_{P}\right)\right) . \\
& \text { s.t. } \boldsymbol{w}^{\prime} \mathbf{1}=1-w_{0}
\end{aligned}
$$


Taking into account first-order conditions for a maximum value ${ }^{\dagger}$ and the two-fund monetary separation theorem, the equilibrium relation becomes (see [34]):

$$
\boldsymbol{E}-R_{f} \mathbf{1}=b_{1} \boldsymbol{\beta}+b_{2} \gamma+b_{3} \boldsymbol{\delta}
$$

i.e. for all securities:

$$
E\left(R_{i}\right)-R_{f}=b_{1} \beta_{i}+b_{2} \gamma_{i}+b_{3} \delta_{i}, i \in\{1,2, \ldots, I\}
$$

where $E\left(R_{i}\right)$ is the expected return on the $i$-th stock, $\beta_{i}=\frac{\operatorname{Cov}\left(R_{i}, R_{m}\right)}{\sigma_{m}^{2}}$, $\gamma_{i}=\frac{\operatorname{Cos}\left(R_{i}, R_{m}\right)}{s_{m}^{3}}, \delta_{i}=\frac{\operatorname{Cok}\left(R_{i}, R_{m}\right)}{\kappa_{m}^{4}}$ and $R_{m}$ is the market return. The variables $b_{1}$, $b_{2}$ and $b_{3}$ are measures of the investor's aversion to variance, preference for skewness and aversion to kurtosis, respectively. The empirical evaluating of the equation (12) for each stock $i$ and for $T$ periods, $t \in\{1,2, \ldots, T\}$, provides the market model:

$$
R_{i t}=\alpha_{i}+\beta_{i} R_{m t}+\gamma_{i} R_{m t}^{2}+\delta_{i} R_{m t}^{3}+\varepsilon_{i t}, i \in\{1,2, \ldots, I\},
$$

where $R_{i t}$ denotes the excess return on the $i$-th stock, $R_{m t}$ excess market return and $\varepsilon_{i t}$ is the error term. In order to determine the impact of the $\beta_{i}, \gamma_{i}$ and $\delta_{i}$ on the investor's utility, the estimates from (13) are used as variables in the relation (12). Thus, the second equation for estimation becomes:

$$
\overline{R_{i}}=\lambda_{0}+\lambda_{1} \beta_{i}+\lambda_{2} \gamma_{i}+\lambda_{3} \delta_{i}+\varepsilon_{i}
$$

where $\overline{R_{i}}$ is the average (excess) return of each stock (portfolio), $\lambda_{1}=\theta_{2} \sigma^{2}\left(R_{M}\right)$, $\lambda_{2}=\theta_{3} S^{3}\left(R_{M}\right), \lambda_{3}=\theta_{4} \kappa^{4}\left(R_{M}\right)$ and $\theta_{j}, j=\{2,3,4\}$, are the market premiums for the respective risks. As given in [37], it should be that $\lambda_{1}>0, \lambda_{3}>0$ with $\lambda_{2}$ having the opposite sign of market skewness. Jurczenko and Maillet [34:122] explain these coefficients as measures of an investor's aversion (for $\theta_{2}$ and $\theta_{4}$ ) or preference $\left(\theta_{3}\right)$ for the $j$-th distribution moment. The next section deals with empirical modelling of the analyzed theoretical foundations.

\section{A methodology for empirical analysis}

The sample contains data on monthly returns of 30 investment funds in Croatia. Data was collected from HRportfolio [25]. The number of observations for the different funds varies (January 1999 - May 2014) given that the funds were founded in different periods. However, the intention is to use all the available

${ }^{\dagger}$ Necessary and sufficient since the Hessian matrix of the objective function is negative definite. 
data (see table in appendix). Open stock funds were considered in the analysis. All of the calculations were performed in Excel and the estimation was done in EVeiws. Given the daily returns, we can calculate the monthly returns $R_{i t}$ of the $i$-th fund in the month of $t, i \in\{1,2, \ldots, 30\}, t \in\left\{1,2, \ldots, n_{i}\right\}$, as an average daily return within a particular month $t$ :

$$
R_{i t}=\frac{\sum_{j=1}^{d_{i t}} r_{j}^{i t}}{d_{i t}},
$$

where $r_{j}^{i t}=\ln P_{j}^{i t} / P_{j-1}^{i t}, j \in\left\{1, \ldots, d_{i t}\right\}$ is the $j$-th daily return in month $t$ and $P_{j}^{i k}$ a $j$-th observation of an daily $N A V$ of the $i$-th fund in the month $t, n_{i}$ is the number of monthly data for the $i$-th fund and $d_{i t}$ is the number of observations for the $i$-th fund in month $t$. Descriptive statistics of a fund's monthly return is analyzed to draw conclusions on a distribution shape. A risk-free rate is approximated using an effective daily value of an average monthly interest rate for 91-day Croatian T-bills, whereas the market return is approximated using a monthly return from the CROBEX index.

Following the methodology presented in [24], we estimate the regressions of (13) for each $i \in\{1,2, \ldots, 30\}$. In order to reach a valid conclusion on whether incorporating higher moments in the CAPM provides a better explanation of the relationship between risk and return, and to which order should it be analyzed, we estimate the modified regressions of (13) by including just some of the regressors: (13-1) $R_{m t},(13-2) R_{m t}, R_{m t}^{2},(13-3) R_{m t}, R_{m t}^{2}, R_{m t}^{3},(13-4) R_{m t}^{2}, R_{m t}^{3}$. Once coefficients $\alpha_{i}, \beta_{i}, \gamma_{i}, \delta_{i}, \forall i$, from (13-1) - (13-4) are estimated, equation (14) can be resolved, where $\overline{R_{i}}$ is the average of $R_{i t}, \forall i \in\{1,2, \ldots, 30\}$, and modifications to (14), adjusted for models (13-1) - (13-4). The absolute values of beta coefficient can be observed since the assumption is that both a large negative and large positive correlation with the market return should be ascertained as risky. A further assumption is that investors prefer positive values for odd moments and negative values for even moments of the return distribution. Therefore, attention will be given to compensation in form of an excess return when the return distribution has the opposite characteristics (and vice versa), hence $\lambda_{j} \geq 0$ if $j$ is an odd number, otherwise $\lambda_{j}<0$.

\section{Results}

To decide whether extending the analysis up to the fourth distribution moment is reasonable, the necessary analysis of the monthly returns is performed with the descriptive statistics of monthly fund returns shown in table (1). The monthly returns are mostly negative, volatile, negatively skewed (asymmetrical distribution with a longer left tail), and in general, peak more than in a 
Gaussian distribution (with a $\mathrm{k}>3$ ). The Jarque-Bera normality test shows that for majority of distributions the hypothesis of normality can be rejected at usual levels of statistical significance.

\begin{tabular}{|l|c|c|c|c|c|c|}
\hline \multicolumn{1}{|c|}{ Investment fund } & Mean & SD $\%$ & Skew & Kurt & Jarque-Bera & $J B$-value \\
\hline A1 & -0.028 & 23.931 & -0.040 & 4.470 & 6.499 & 0.039 \\
\hline CAPITAL TWO & 0.023 & 77.769 & 0.426 & 2.974 & 0.846 & 0.655 \\
\hline ERSTE ADRIATIC & -0.023 & 19.105 & -0.852 & 3.898 & 13.131 & 0.001 \\
\hline FIMA EQUITY & -0.014 & 25.435 & -0.778 & 6.286 & 56.751 & 0.000 \\
\hline HI GROWTH & -0.002 & 20.045 & -1.509 & 7.214 & 164.527 & 0.000 \\
\hline HPB DIONICKI & -0.006 & 23.615 & -0.834 & 6.164 & 55.441 & 0.000 \\
\hline ILIRIKA AZIJSKI TIGAR & -0.048 & 24.294 & -0.840 & 4.013 & 13.460 & 0.001 \\
\hline ILIRIKA BRIC & -0.032 & 21.150 & -0.199 & 3.176 & 0.418 & 0.811 \\
\hline ILIRIKA JIE & 0.011 & 23.764 & -0.242 & 4.306 & 9.296 & 0.010 \\
\hline KD ENERGIJA4 & 0.000 & 18.519 & -0.649 & 4.061 & 5.975 & 0.050 \\
\hline KD NOVA EUROPA & -0.036 & 30.925 & -1.044 & 5.476 & 34.530 & 0.000 \\
\hline KD PRVI IZBOR & 0.007 & 11.029 & -1.232 & 9.539 & 274.664 & 0.000 \\
\hline KD VICTORIA & 0.014 & 27.374 & -0.404 & 4.622 & 24.097 & 0.000 \\
\hline NETA FRONTIER & 0.014 & 13.925 & 0.018 & 2.666 & 0.353 & 0.838 \\
\hline NETA GLOBAL & 0.000 & 25.725 & -2.121 & 12.088 & 427.448 & 0.000 \\
\hline NETA NEW EUROPE & -0.019 & 22.570 & -0.569 & 3.794 & 5.377 & 0.068 \\
\hline NETA US ALGORITHM & 0.026 & 27.395 & -0.246 & 3.307 & 0.936 & 0.626 \\
\hline OTP INDEKSNI & -0.063 & 36.747 & -1.050 & 7.467 & 78.189 & 0.000 \\
\hline OTP MERIDIAN 20 & -0.009 & 24.462 & -0.435 & 5.293 & 18.294 & 0.000 \\
\hline PBZ EQUITY FOND & -0.015 & 28.095 & -0.808 & 7.422 & 96.953 & 0.000 \\
\hline PBZ I STOCK1 & -0.035 & 31.013 & -1.952 & 10.325 & 200.959 & 0.000 \\
\hline PLATINUM BLUE CHIP & -0.002 & 13.570 & -0.630 & 3.494 & 6.110 & 0.047 \\
\hline PLATINUM GLOBAL OP & -0.016 & 21.542 & -0.324 & 3.098 & 1.436 & 0.488 \\
\hline RAIFFEISEN NEW & 0.019 & 10.063 & -0.717 & 4.868 & 6.705 & 0.035 \\
\hline RAIFFEISEN WORLD & -0.031 & 31.162 & -1.495 & 8.526 & 179.247 & 0.000 \\
\hline VB CROBEX & -0.022 & 22.899 & 0.927 & 5.538 & 21.407 & 0.000 \\
\hline ZB AKTIV & -0.005 & 24.121 & -0.695 & 5.784 & 38.325 & 0.000 \\
\hline ZB BRIC & -0.009 & 17.360 & -0.025 & 3.785 & 1.265 & 0.531 \\
\hline ZB EUROAKTIV & 0.011 & 16.482 & -0.717 & 3.688 & 12.749 & 0.002 \\
\hline ZB TREND & 0.011 & 12.238 & -0.586 & 3.251 & 8.319 & 0.016 \\
\hline Index CROBEX & 0.0327 & 36.487 & -0.660 & 7.977 & 194.42 & 0.000 \\
\hline
\end{tabular}

Table 1: The descriptive statistic of the fund's monthly returns 


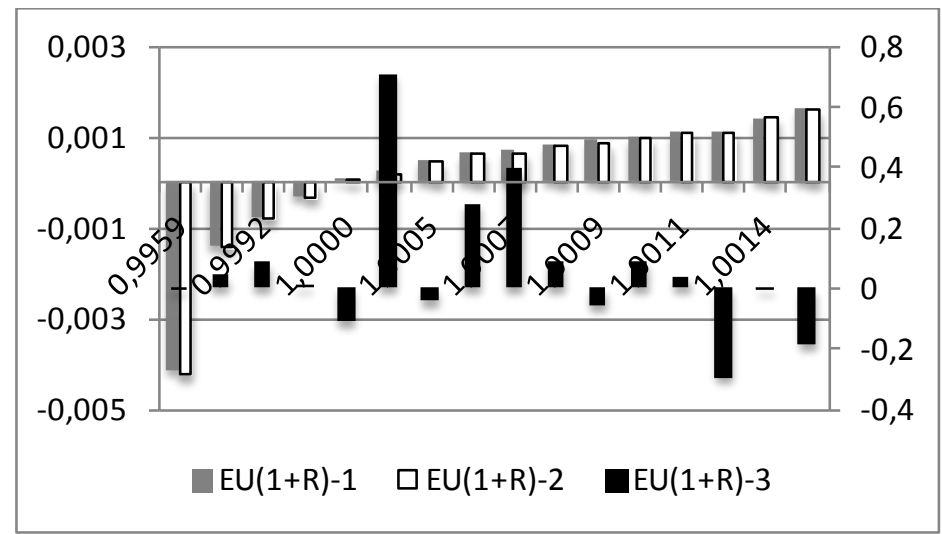

Note: $\mathrm{EU}(1+\mathrm{R})-i, i \in\{1,2,3,4\}$ denotes the expected utility of return with the included first $i$-th moments.

Figure 1: The utility of yearly portfolios with respect to various higher moments, Fund 13

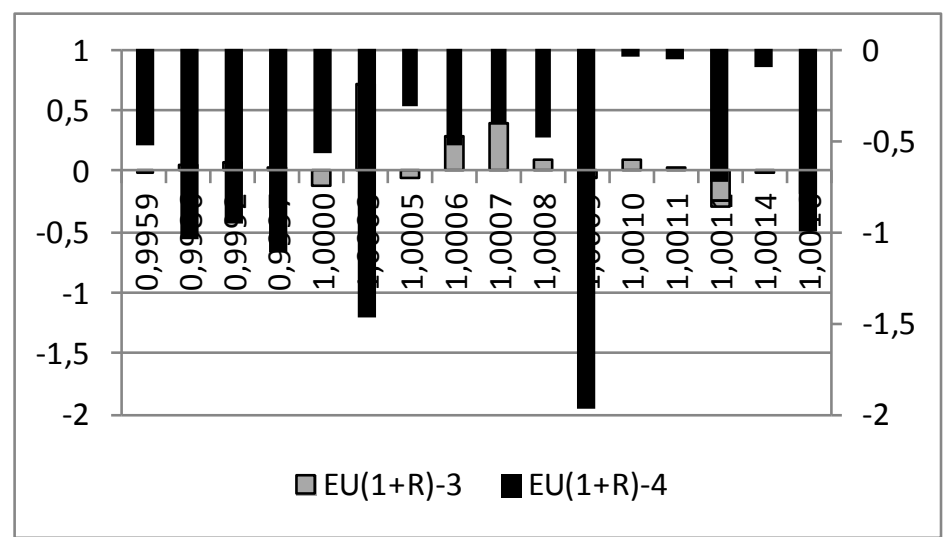

Note: $\mathrm{EU}(1+\mathrm{R})-i, i \in\{1,2,3,4\}$ denotes the expected utility of return with the included first $i$-th moments.

Figure 2: The utility of yearly portfolios with respect to various higher moments, Fund 13

The utilities ${ }^{\ddagger} U\left(R_{i t}\right), \forall i \in\{1,2, \ldots, 30\}$ were calculated using (4) and using (6), (7) and (8), where $\gamma=10$ and $\lambda=2$ are chosen arbitrarily (the coefficient values are irrelevant for this analysis). By incorporating higher moments (4) and adding the third and fourth moments in the analysis (Figures 1 and 2) leads to significantly different values of the utility functions, which in turn, alters the sequence of the yearly portfolios ${ }^{\S}$ (Table 2). Fund 13 was chosen arbitrarily (other funds yielded similar values). Figure 2 shows that all chosen utility

\footnotetext{
$\ddagger$ Other utilities were omitted due to limited paper size, but are available upon request.

$\S$ Yearly data was calculated similar as in (15).
} 
functions ranked yearly data of various portfolios in the same manner when only first (M1) and second (M2) moments were considered, but rankings change and differ between different functions when higher moments are added. According to the theory however, as the signs of $U^{(n)}(R)$ in (4), which express preference for a certain moment, are given by functions (5), (6) and (7), Figures (1) and (2) show the manner in which the utility changes subject to higher distribution moments. On the other hand, there exists some curiosity as to whether the use of these theoretical utility functions is empirically justified.

\begin{tabular}{|c|c|c|c|c|c|c|c|c|c|c|c|c|c|c|c|c|}
\hline Y (1999-2014) & $\mathbf{9 9}$ & $\mathbf{0 0}$ & $\mathbf{0 1}$ & $\mathbf{0 2}$ & $\mathbf{0 3}$ & $\mathbf{0 4}$ & $\mathbf{0 5}$ & $\mathbf{0 6}$ & $\mathbf{0 7}$ & $\mathbf{0 8}$ & $\mathbf{0 9}$ & $\mathbf{1 0}$ & $\mathbf{1 1}$ & $\mathbf{1 2}$ & $\mathbf{1 3}$ & $\mathbf{1 4}$ \\
\hline \hline $\boldsymbol{R}_{\boldsymbol{y}}$ & 0.070 & 0.025 & 0.163 & 0.093 & 0.002 & 0.142 & 0.085 & 0.098 & 0.109 & -0.412 & -0.141 & -0.033 & -0.078 & 0.049 & 0.064 & 0.109 \\
\hline $\boldsymbol{\sigma}^{\mathbf{2}}$ & 0.013 & 0.021 & 0.009 & 0.017 & 0.003 & 0.002 & 0.006 & 0.002 & 0.004 & 0.020 & 0.010 & 0.006 & 0.005 & 0.004 & 0.004 & 0.003 \\
\hline $\mathbf{s}^{\mathbf{3}}$ & 1.180 & 2.129 & -0.573 & -0.180 & -0.340 & -0.026 & 0.263 & 0.264 & -0.890 & -0.014 & 0.133 & 0.012 & 0.256 & -0.138 & 0.836 & 0.115 \\
\hline $\mathbf{k}^{4}$ & 6.455 & 17.404 & 6.502 & 15.356 & 3.683 & 0.742 & 4.613 & 0.993 & 3.450 & 4.077 & 8.627 & 8.872 & 8.280 & 2.073 & 6.493 & 0.747 \\
\hline \hline M1 & 8 & 11 & 1 & 6 & 12 & 2 & 7 & 5 & 3 & 16 & 15 & 13 & 14 & 10 & 9 & 4 \\
\hline M2 & 8 & 11 & 1 & 6 & 12 & 2 & 7 & 5 & 4 & 16 & 15 & 13 & 14 & 10 & 9 & 3 \\
\hline DARA M3 & 2 & 1 & 15 & 13 & 14 & 10 & 5 & 4 & 16 & 11 & 7 & 9 & 6 & 12 & 3 & 8 \\
\hline DARA M4 & 5 & 15 & 12 & 16 & 9 & 3 & 6 & 1 & 10 & 7 & 13 & 14 & 11 & 4 & 8 & 2 \\
\hline CRRA M3 & 2 & 1 & 15 & 13 & 14 & 10 & 5 & 4 & 16 & 11 & 7 & 9 & 6 & 12 & 3 & 8 \\
\hline CRRA M4 & 9 & 16 & 11 & 15 & 6 & 2 & 8 & 3 & 5 & 7 & 13 & 14 & 12 & 4 & 10 & 1 \\
\hline CARA M3 & 2 & 1 & 15 & 13 & 14 & 11 & 5 & 4 & 16 & 10 & 7 & 9 & 6 & 12 & 3 & 8 \\
\hline CARA M4 & 6 & 1 & 8 & 2 & 11 & 16 & 9 & 14 & 12 & 10 & 4 & 3 & 5 & 13 & 7 & 15 \\
\hline
\end{tabular}

Table 2: Sequence of yearly portfolios based on their utilities for different years, Fund 13

Therefore, the relationship between excess return and distribution moments requires estimating variations of model (13) and model (14). For (13-1) the following estimates were obtained:

\begin{tabular}{|l|l|l|l|l|l|}
\hline Variable & Coefficient & Prob. & $R^{2}$ & Adj $R^{2}$ & $Q(12)$ \\
\hline C & -0.095417 & 0.0000 & 0.043441 & 0.009278 & 4.3418 \\
\hline ABS(BETA) & -0.028662 & 0.2690 & & & \\
\hline
\end{tabular}

Table 3: Coefficient estimates of model (13-1)

Alpha is significantly different from zero and the beta coefficient is negative (all beta values are positive, so taking absolute values does not disturb the CAPM theory), which obviously does not comply with the theory nor our assumptions. Moreover, the value $\lambda_{1}=-0.028662$ indicates a negative value and insignificant relationship between systematic risk and return. The small value of $R^{2}$ shows that a 2-moment CAPM (13-1) does not explain adequately the excess return variations from investment funds on the Croatian stock market. 
Incorporating systematic skewness (13-2), and both systematic skewness and kurtosis (13-3) provides new coefficient estimates as shown in Table 4.

\begin{tabular}{|c|c|c|c|c|c|c|}
\hline & Variable & Coefficie & Prob. & $R^{2}$ & Adj $R^{2}$ & $Q(12)$ \\
\hline \multirow{2}{*}{$\begin{array}{c}\text { Model } \\
(13-2)\end{array}$} & $\mathrm{C}$ & -0.09573 & 0 & 0.040712 & -0.03035 & 4.2041 \\
\cline { 2 - 7 } & ABS(BETA) & -0.02769 & 0.3276 & & & \\
\cline { 2 - 7 } & GAMMA & 0.00118 & 0.9697 & & & \\
\hline \hline \multirow{2}{*}{$\begin{array}{c}\text { Model } \\
(13-3)\end{array}$} & $\mathrm{C}$ & -0.093148 & 0.0000 & 0.510962 & 0.454534 & 3.9130 \\
\cline { 2 - 7 } & ABS(BETA) & -0.044520 & 0.0427 & & & \\
\cline { 2 - 7 } & GAMMA & 0.036745 & 0.0369 & & & \\
\cline { 2 - 7 } & DELTA & 0.024495 & 0.0002 & & & \\
\hline
\end{tabular}

Table 4: Coefficient estimates of models (13-2) and (13-3)

The model (13-2) has a smaller adjusted $R^{2}$ than model (13-1), while $\lambda_{1}$ and $\lambda_{2}$ indicate an insignificant relationship between excess return and beta or systematic skewness. Model (13-3) gives best estimates and a model that describes the variations better than previous models. Therefore, model (13-3) leads to the conclusion that a significant negative relationship exists between excess return and absolute beta, as well as a positive significant relationship between excess return and both systematic skewness and systematic kurtosis. Thomas [58] for the Bombay Stock Exchange and Hasan et al. [18] for Bangladesh Stock Market found an insignificant negative relationship between beta and excess return, whereas Mecagni and Sourial [46] found that a significant positive relationship for the Egyptian Stock Exchange. ${ }^{* *}$ Therefore, there is no market premium for extra variance on the Croatian capital market, which contradicts the theory. However, since market skewness is negative, a positive sign for $\lambda_{2}$ and $\lambda_{3}$ supports the theory, and investors are compensated for undesirable, non-diversifiable systematic skewness and kurtosis. In addition, if the coefficients for $\beta, \gamma$ and $\delta$ are used to interpret preferences of investment funds for variance, skewness and kurtosis according to Jurczenko and Maillet [34], Croatian investment funds should prefer variance and have an aversion to skewness and kurtosis, meaning that theoretical utility functions cannot be used to measure utility.

\section{Conclusion}

Current finance theory and asset pricing models rely on the assumption that higher distribution moments should be considering for investor preferences. The justification can be found in microeconomic theory and empirical research, throughout the past couple of decades. For this reason, traditional evaluation

\footnotetext{
** Similar research is presented in Messis et al. [41] and Attiya and Eatzaz [8], but the methodologies are not comparable in this instance.
} 
models of stock and portfolio become inconsistent and need to be revised. Up until now, research for Croatia has relied on the first two distribution moments: return and variance. This paper endeavours to include the third (skewness) and the fourth (kurtosis) moments when empirically evaluating investor utility functions, and reliance is also placed on the famous Capital Asset Pricing Model. Here, focused has been placed on Croatian investment funds for the period January 1999 - May 2014, and three types of utility functions with desired properties have been applied. The inclusion of the third and fourth moment into the utility function significantly changes the actual utilities and the orderings, implying that including higher moments in the analysis makes a great difference, and consequently questions the validity of conclusions drawn from all models that consider solely the first two moments. Moreover, the basic $\mathrm{CAPM}$ and higher-moment CAPM were analyzed in order to comprehend whether including higher moments contributes significantly providing an explanation of the relationship between risk and excess return. The results indicated that a negative relationship exists between risk (variance) and reward, whereas a positive relationship exists between reward and the systematic third and fourth moment. Therefore, greater systematic variance on Croatian market cannot explain the greater returns. However, the risk posed from systematic asymmetry and kurtosis does explain excess return. The theory leads to the conclusion that investors should prefer variance and have an aversion to systematic asymmetry and kurtosis. Finally, this implies that using theoretical utility functions in financial models can be misleading. The research is subject to some limitations. The sole observed market index was CROBEX. Funds are regularly invested in foreign countries as well. Thus, further research would include other market indices in the analysis. Nonetheless, the conclusion is that investors in Croatia do not adhere to behaviour as explained in microeconomic theory.

\section{References}

[1] Adcock, C. J. (2005). Exploiting skewness to build an optimal hedge fund with a currency overlay. European Journal of Finance, 11(5), 445-462. doi:10.1080/13518470500039527.

[2] Arditti, F. (1967). Risk and the required return on equity. Journal of Finance, 22(1), 19-36. doi:10.1111/j.1540-6261.1967.tb01651.x.

[3] Arditti, F. (1971). Another look at mutual fund performance. Journal of Financial Quantitative Analysis, 6(3), 913-924. doi:10.2307/2329910.

[4] Arditti, F. and Levy, H. (1975). Portfolio efficiency analysis in three moments: The multiperiod case. Journal of Finance, 30(3), 797-809. doi:10.2307/2326859.

[5] Arrow, K. (1970). Essays in the Theory of Risk Bearing. North-Holland Publishing Company. Amsterdam - London. 
[6] Athayde, G. and Flôres, R. (1997). A CAPM with higher moments: Theory and econometrics. Discussion Paper EPGE-FGV.

[7] Athayde, G. and Flores, R. (2004). Finding a maximum skewness portfolio: A general solution to three-moments portfolio choice. Journal of Economic Dynamics \& Control 28, 1335-1352. doi:10.1016/s0165-1889(02)00084-2.

[8] Attiya Y. J. and Ahmad, E. (2008). Test of multi-moment capital asset pricing model: Evidence from Karachi Stock Exchange. PIDE Working Papers 2008:49.

[9] Brandouy, O., Briec, W., Kerstens, K., and Van de Woestyne, I. (2010). Portfolio performance gauging in discrete time using a Luenberger productivity indicator. Journal of Banking \& Finance, 34, 1899-1910. doi:10.1016/j.jbankfin.2009.12.015.

[10] Briec, W., Kerstens, K. and Jokung, O. (2006). Mean-variance-skewness portfolio performance gauging: A general shortage function and dual approach. Management Science, 53(1), 135-149. doi:10.1287/mnsc.1060.0596.

[11] Briš, M., Kristek, I. and Mijoč, I. (2008) Election of optimal portfolio by use of risk diverzificaton method. Interdisciplinary management research IV, Faculty of Economics in Osijek, Osijek, 329-343.

[12] Chang, Y. P., Johnson, H. and Schill, M. J. (1998). The econometrics of financial markets. Macroeconomic Dynamics, 2(4), 559-562.

[13] Chunhachinda, P., Dandaphani, K., Hamid, S. and Prakash, A. J. (1997). Portfolio selection and skewness: Evidence from international stock markets. Journal of Banking and Finance, 21, 143-167. doi:10.1016/s0378-4266(96)00032-5.

[14] Cootner, P. (Ed.) (1964). The Random Character of Stock Market Prices. MIT Press.

[15] Dittmar, R. (2002). Nonlinear pricing kernels, kurtosis preference and evidence from the cross-section of equity returns. Journal of Finance, 57(1), 369-403. doi:10.1111/1540-6261.00425.

[16] Džaja, J. and Aljinović, Z. (2013). Testing CAPM model on the emerging markets of the Central and Southeastern Europe. Croatian Operational Research Review (CRORR), 4, 164-175.

[17] Fama, E. (1965). The behavior of stock-market prices. Journal of Business 38(1), 34-105. doi:10.1086/294743.

[18] Fama, E. and French, K. (1995). Size and book-to market factors in earnings and returns. Journal of Finance, 50(1), 131-155. doi:10.2307/2329241.

[19] Fang, H. and Lai, T. Y. (1997). Co-kurtosis and capital asset pricing. The Financial Review, 32(2), 293-307. doi:10.1111/j.1540-6288.1997.tb00426.x.

[20] Fruk, M. and Huljak, I. (2004). Testiranje Sharpe-Linterova modela na Zagrebačkoj burzi (Testing out the Sharpe-Lintner model on the Zagreb Stock Exchange). Financijska teorija i praksa (Financial Theory and Practice), 28(1), 77-91.

[21] Graddy, D. and G. Homaifar (1988). Equity yields in models considering higher moments of the return distribution. Applied Economics, 20(3), 325-334. doi:10.1080/00036848800000046.

[22] Guidolin, M. and Timmermann, A. (2005). Optimal portfolio choices under regime switching, skew and kurtosis preferences. Working Paper, Federal Reserve Bank of St Louis.

[23] Harvey, C. and Siddique, A. (2000). Conditional skewness in asset pricing tests. The Journal of Finance, 55(3), 1263-1295. doi:10.1111/0022-1082.00247. 
[24] Hasan, Z., Abdulbasah Kamil, A., Mustafa A. and Baten A. (2013). An empirical analysis of higher moment capital asset pricing model for Bangladesh stock market. Modern Applied Science, 7(5), 11-21. doi:10.5539/mas.v7n5p11.

[25] HRPortfolio (2014). http://www.hrportfolio.hr. [Accessed on 16 August 2014]

[26] Hwang, S. and Satchell, S. (1999). Modeling emerging market risk premia using higher moments. International Journal of Finance and Economics, 4(4), 271-296.

[27] Ingersoll, J. (1975). Multidimensional security pricing. Journal of Financial and Quantitative Analysis, 10, 785-798. doi:10.2307/2330271.

[28] Jean, W. (1971). The extension of portfolio analysis to three and more parameters. Journal of Financial and Quantitative Analysis, 6(1), 505-515. doi:10.2307/2330125.

[29] Jean, W. (1972). Distribution moments and equilibrium: Reply. Journal of Financial and Quantitative Analysis, 7, 1435-1437. doi:10.2307/2330077.

[30] Jean, W. (1973). More on multidimensional portfolio analysis. Journal of Financial and Quantitative Analysis, 8(3), 475-490. doi:10.2307/2329646.

[31] Jegadeesh, N. (1992). Does market risk really explain the size effect? Journal of Financial and Quantiative Analysis, 27(3), 337-351. doi:10.2307/2331323.

[32] Jondeau, E. and Rockinger, M. (2006). Optimal portfolio allocation under higher moments. European Financial Management, 12(1), 29-55. doi:10.1111/j.13547798.2006.00309.x

[33] Jurczenko, E. and Maillet, B. (2005). The Four-moment Capital Asset Pricing Model: Between Asset Pricing and Asset Alocation. Springer-Verlag.

[34] Jurczenko, E. and Maillet, B. (2006). Multi-moment Asset Allocation and Pricing Models. England: John Wiley \& Sons, Ltd.

[35] Kabatchenko Nielsen, E. (2008). Efficient Portfolio Selection in Mean-VarianceSkewness Space. Arhus Handelshojskole, Arhus Universitet.

[36] Kemalbay, G., Özkut, C. M. and Franko, C. (2011). Porfolio selection with higher moments: A polynomial goal programming approach to ISE-30 index. Ekonometri ve Istatistik Sayı: 13, 41-61.

[37] Kimball, M. (1993). Standard risk aversion. Econometrica, 61(3), 589-611. doi:10.2307/2951719

[38] Lai, T. (1991). Portfolio with skewness: A multiple-objective approach. Review of Quantitative Finance and Accounting, 1(3), 293-305. doi:10.1007/bf02408382.

[39] Lhabitant, F. (1997). On the (ab)use of expected utility approximations for portfolio selection and portfolio performance. Working Paper, University of Lausanne.

[40] Lintner, J. (1965). The valuation of risk assets and the selection of risky investments in stock portfolios and capital budgets. Review of Economics and Statistics, 47(1), 13-37. doi:10.2307/1924119.

[41] Liu, M. and Wu, F. F. (2007). Portfolio optimization in electricity markets. Electric Power System Research, 77(8), 1000-1009. doi:10.1016/j.epsr.2006.08.025.

[42] Mandelbrot, B. (1963a). The variation of certain speculative prices. Journal of Business 36(4), 394-419. doi:10.1086/294632.

[43] Mandelbrot, B. (1963b). New methods in statistical economics. Journal of Political Economy, 71(5), 421-440. doi:10.1086/258792.

[44] Marasović, B. and Šego, B. (2006). Markowitzev model optimizacije portfelja (The Markowitz Model of portfolio optimization). Računovodstvo i financije (Accounting and Finance), LII (2006), 57-61. 
[45] Markowitz, H. (1952). Portfolio selection. The Journal of Finance, 7(1), 77-91. doi:10.1111/j.1540-6261.1952.tb01525.x.

[46] Mecagni, M. and Sourial, M. S. (1999). The Egyptian stock market: Efficiency tests and volatility effects. IMF Working Papers 99/48, International Monetary Fund.

[47] Messis, P., Iatrids, G. and Blanas, G. (2007). CAPM and the efficacy of higher moment CAPM in the Athens stock market: An empirical approach. International Journal of Applied Economics, 4, 60-75.

[48] Müller, S. M. and Machina, M. J. (1987). Moment preferences and polynomial utility. Economics Letters, 23, 349-353. doi:10.1016/0165-1765(87)90143-1.

[49] Perković, A. (2011). Research of beta as adequate risk measure - is beta still alive? Croatian Operational Research Review (CRORR), 2, 102-111.

[50] Prakash, A. J., Chang, C.H. and Pactwa, T. E. (2003). Selecting a portfolio with skewness: Recent evidence form US, European and Latin American equity markets. Journal of Banking \& Finance 27(7), 1375-1390. doi:10.1016/s0378-4266(02)00261-3.

[51] Pratt, J. (1964). Risk aversion in the small and the large. Econometrica, 32, 122136. doi:10.2307/1913738.

[52] Roll, R. (1977). A critique of the asset pricing theory's tests. Journal of Financial Economics 4, 129-176. doi:10.1016/0304-405x(77)90009-5.

[53] Ross, S. (1977). The capital asset pricing model, short sales restriction and related issues. Journal of Finance, 32, 177-183. doi:10.2307/2326912.

[54] Rubinstein, M. (1973). The fundamental theorem of parameter-preference security valuation. Journal of Financial and Quantitative Analysis, 8(1), 61-69. doi: $10.2307 / 2329748$.

[55] Samuelson, P. (1970). The fundamental approximation theorem of portfolio analysis in terms of means, variances and higher moments. Review of Economic Studies, 37, 537-543. doi: $10.2307 / 2296483$.

[56] Scott, R. C. and Horvath, P. A. (1980). On the direction of preference for moments of higher order than the variance. Journal of Finance, 35, 915-919. doi:10.1111/j.1540-6261.1980.tb03509.x.

[57] Sharpe, W. F. (1964). Capital asset prices: A theory of market equilibrium under conditions of risk. Journal of Finance, 19(3), 425-442. doi:10.1111/j.15406261.1964.tb02865.x.

[58] Thomas, S. (1995). Heteroskedasticity models on the Bombay Stock Exchange. PhD Dissertation, University of Southern California. 


\section{APPENDIX}
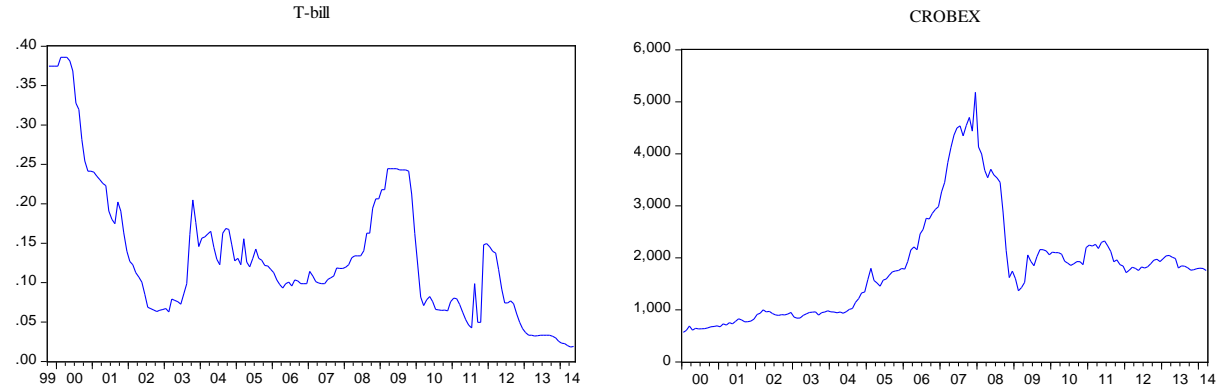

Figure 1 and 2: Monthly data on Treasury bill interest rate and CROBEX

\begin{tabular}{|c|c|c|c|}
\hline Fund & Start date & Fund & Start date \\
\hline A1 & June 2008 & Neta New Europe & November 2008 \\
\hline Capital two & February 2012 & Neta US Algorithm & November 2008 \\
\hline Erste Adriatic Equity & May 2007 & OTP Indeksni & January 2008 \\
\hline Fima Equity & October 2005 & OTP Meridian & May 2008 \\
\hline HI Growth & March 2002 & PBZ Equity fund & September 2005 \\
\hline HPB Dionički & October 2005 & PBZ I Stock & August 2008 \\
\hline Ilirika Azijski tiger & June 2007 & Platinum blue chip & October 2007 \\
\hline Ilirika BRIC & January 2010 & Platinum global opportunity & October 2007 \\
\hline Ilirika JIE & November 2004 & Raiffeisen New Europe & January 2012 \\
\hline KD Energija & March 2010 & Raiffeisen World & May 2005 \\
\hline KD Nova Europa & November 2007 & VB Crobex & February 2010 \\
\hline KD Prvi Izbor & March 2003 & ZB Aktiv & July 2006 \\
\hline KD Victoria & October 1999 & ZB Bric & May 2010 \\
\hline Neta Frontier & March 2008 & ZB Euroaktiv & May 2004 \\
\hline Neta Global Developed & December 2005 & ZB trend & November 2002 \\
\hline
\end{tabular}

Table 1. Starting dates of available data for each fund 